\title{
Policy Implications of Shale Gas Research in Collaboration Network Analysis
}

\author{
Jie Liu ${ }^{1, a^{*}}$, Tieju Ma ${ }^{1, b}$ \\ ${ }^{1}$ School of Business, East China University of Science and Technology, Shanghai, Meilong Road \\ 130, 200237, People's Republic of China. \\ aahliujie@126.com, btjma@ecust.edu.cn
}

\begin{abstract}
Keywords: Shale gas, Cooperation network, Bibliometric study, Social network Abstract. Shale gas as an increasingly important form of hydrocarbon energy raises natural gas occupancy and reduces carbon emission in North American, attracting more and more focus all over the world. The main purpose of this paper is to identify the differences in cooperation network in shale gas research and development pattern between China and the USA. The results show that: The USA has more institutes participating in shale gas research, and the institute's collaboration network in America is denser than China's. We suggested that China should foster domestic research force, and depend on nation owned companies and institutes to get innovation.
\end{abstract}

\section{Introduction}

Shale gas, which is a kind of unconventional natural gas extracted from shale formation, has already become an important source of natural gas in North America ${ }^{[1]}$. According to Energy Information Administration (EIA, 2013) ${ }^{[2]}$, the world's identified technically recoverable shale gas will add approximately 47 percent to the global natural gas, and China has the most reserves all over the world. It is expected that shale gas will come to play a large role in solving the problem of worldwide energy shortage and will become a signficant part of the energy mix policy of many countries. Researchers also believed that shale gas exploitation makes natural gas generation to replace coal-based power and then help to reduce carbon emission to some extent to some extent. Since the importance of shale gas in future energy competition, more and more countries started to pay attention to shale gas research and development.

Because of the increasing interests in this field, many research about policy and economic effects of shale gas have been done in recent years. Sultan $(2013)^{[3]}$, Jenner $(2013)^{[4]}$, Lee $(2014)^{[1]}$ and Zhang $(2014)^{[5]}$ had done useful work in this field. Although China has vast shale gas resource, the lack of key advanced exploitation technologies has severely hindered its development (Lee (2014)). However, as many patent owners in China are university, we believed that papers are also important carriers of innovation. Little studies have explored the science research situation of shale gas in the world to acquire useful R\&D suggestions for China.

The main purpose of this paper is to get policy implication by identifying the differences of research collaboration situation between the USA and China. As America was the only country who had accomplished shale gas' large scale commercialization, we believed that American development pattern could give useful enlightenment to China. The rest of the paper is organized as follows. Section two introduces the methods and data source. Section three and four introduces the results of analysis. Section five gives some concluding remarks and policy implications.

\section{Method and Data Source}

To get the cooperation network, we use WoS SCI-E database to collect science research with the key word "shale gas", from 1999 to 2014, the total amount of papers is 2815.

The main method used in this paper is social network analysis. Research institutes were seen as the vertices of collaboration network in this article. When two different institutions emerged in one paper, they were seen as collaborating, so there will be an edge between two of them. Institutes with only one paper were excluded from network. 


\section{Statistical analysis results}

Fig. 1 shows that the annual publishing amount has a signature raise from 2008, especially after 2010, this result responds to the increasing focus on shale gas among scientists.

If we use the basic Price curve equation to fitting the raising curve of annual publishing amount, setting 1999 as the initial year, we can get the regression equation as:

$$
N_{\mathrm{t}}=68 * e^{0.1295 *(\mathrm{t}-1999)}
$$

Which means that the total average growth rate of shale gas paper from 1999-2014 is $12.95 \%$.

There are 86 different countries and regions taking part in science research in the area of shale gas. 6 countries had more than 100 pieces of paper in SCI-E database. The USA with 1079 papers has the absolute advantages in amount, and China ranking to the second had 439 papers from 1999 to 2014. China got the distinct higher position in the publications number from 2011(Fig. 2). Price Curve to fit the growth rate of China and America, getting the equation:

$$
N_{\mathrm{t}(\text { China })}=6 * e^{0.1917 *(\mathrm{t}-1999)}
$$

$$
N_{\mathrm{t}(U S A)}=15 * e^{0.1926 *(\mathrm{t}-1999)}
$$

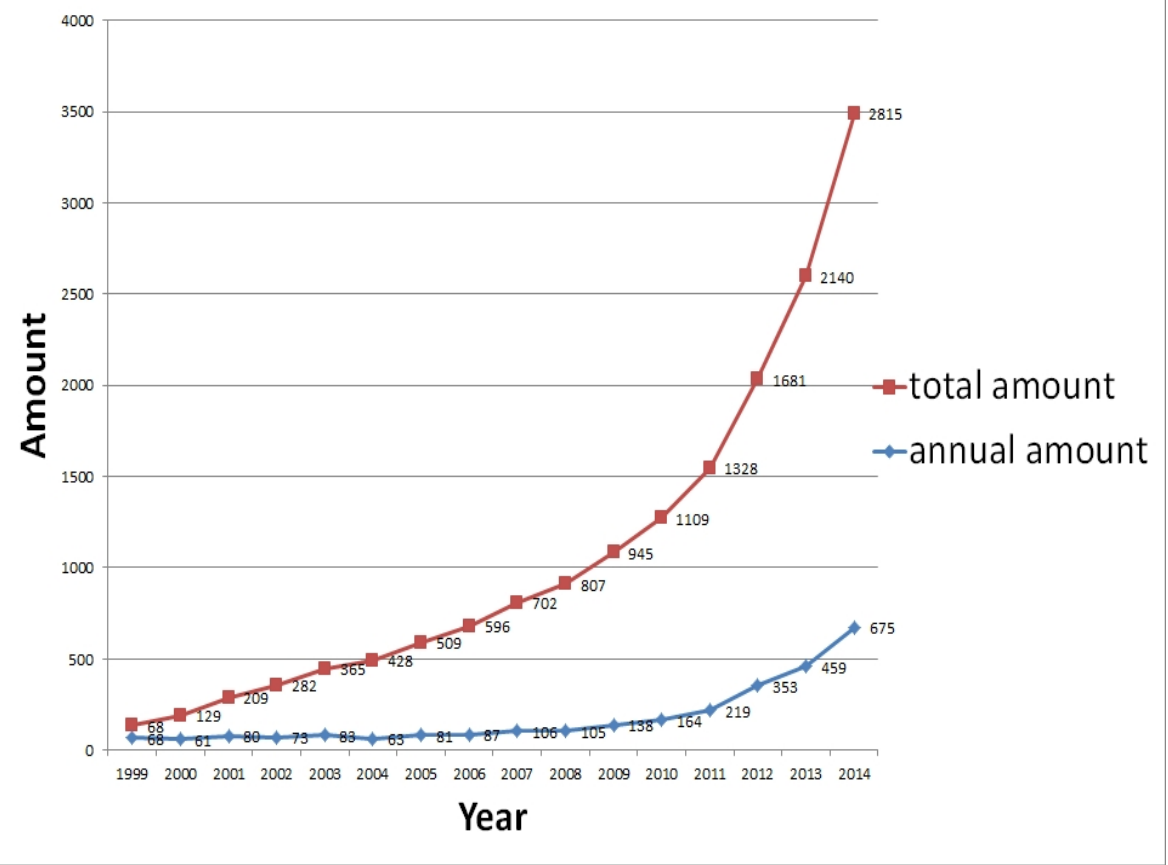

Fig. 1 The amount of publications over calendar years 


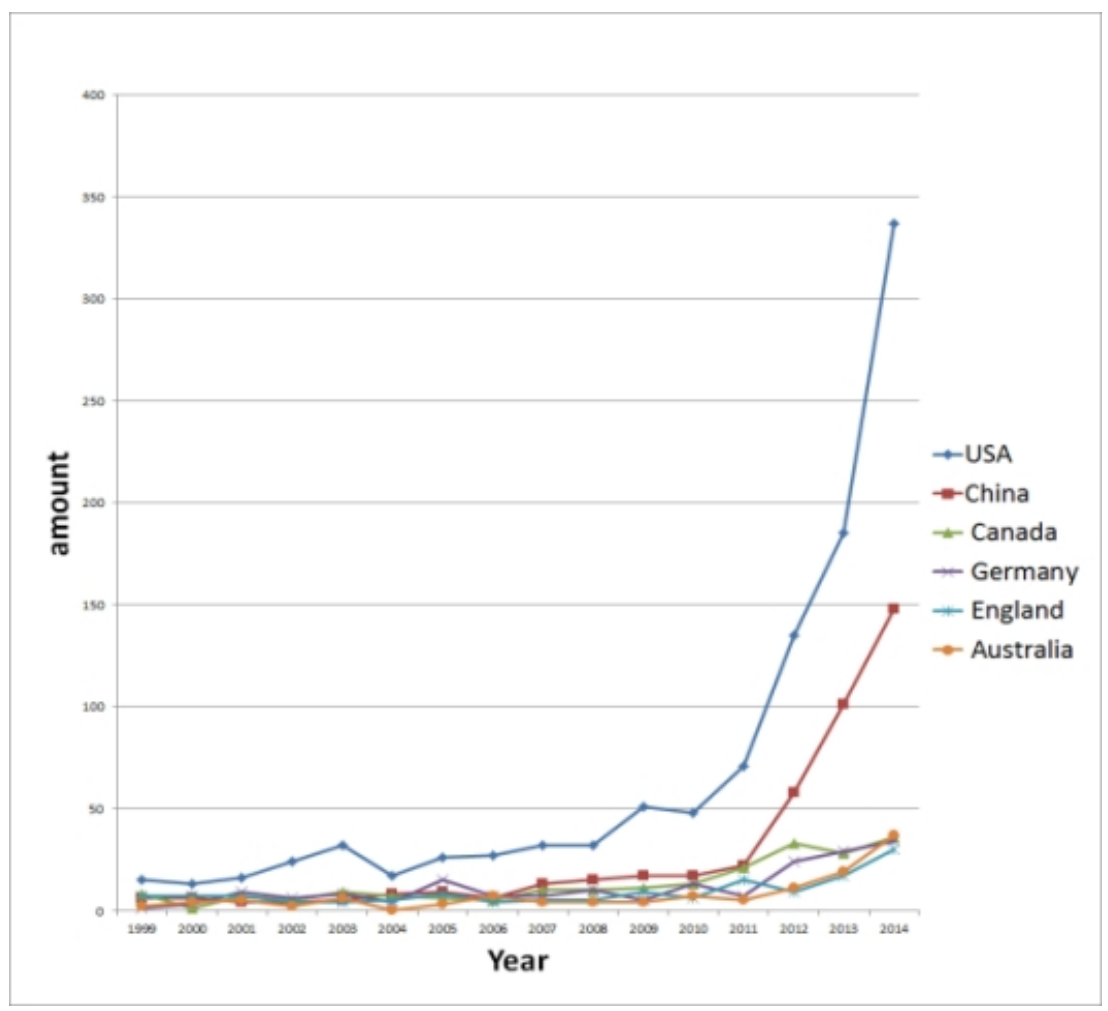

Fig. 2 the amounts of publications over calendar years in six countries with most articles. America and China both had high growth rate, but China get the distinct position just from 2011.

\section{Institutes collaboration network analysis}

Network in 2014 was analyzed to reveal the recent collaboration situation. Majority institutes in Fig.3(a) are Chinese universities or companies, and we can catch the three cores, Chinese Acad Sci ,China Univ Geosci and China Univ Petr, in it directly.

Fig.3(b) show the clusters with American institutes, in which we can see the remarkable differences among China and American research collaboration situation. America as the first country developing shale gas at large scale has the densest network and the highest average degree of collaboration network.

23 institutes in American domestic collaboration network were energy related companies, such as Resources Future Inc, NorthWorks Inc, Chevron Energy Technol Co and so on. The companies participating in shale gas research in China, PetroChina, CNPC and Sinopec, are all owned by state.

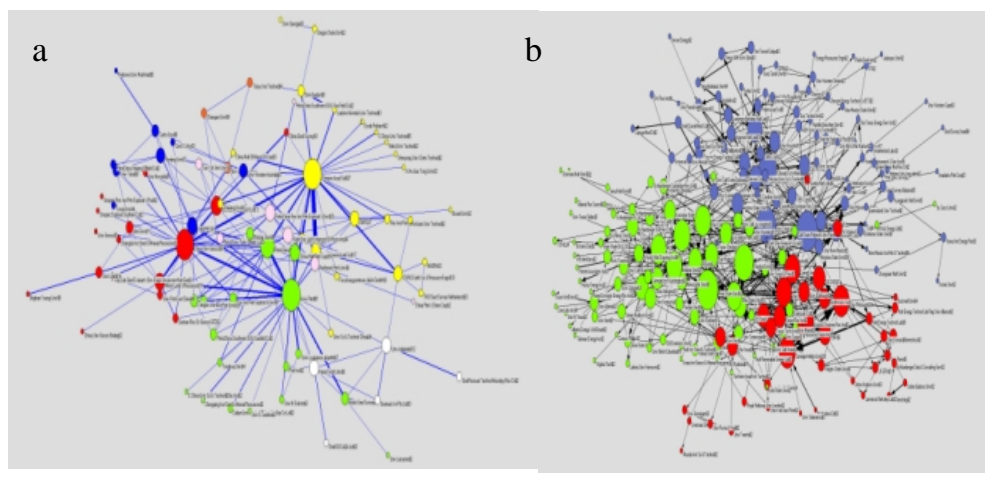

Fig. 3 Institutes collaboration network in the period of 1999-2014. (a) Collaboration network cluster with Chinese institutes ;(b) collaboration network cluster with American institutes; 


\section{Conclusion and policy implication}

The bibliometric study in this paper got following findings:

(1) The USA is the leading country in the amount of science paper of shale gas publication from 1999, and China got the distinct leading position from 2011.

(2)China has a little higher growth rate than the USA, which illustrated the heat focus on shale gas research in China.

The USA has more institutes participating in shale gas research. Universities, nation owned companies and other national institutes consisted in the Chinese research group. The state of China played an extremely important role in Chinese shale gas research. However, universities and private companies dominated shale gas research in the USA.

Comparing with the USA, we got some implications for China's shale gas research:

(1) Domestic research forces need to be fostered, because we can see there was an extremely dense institute collaboration network in the USA.

(2) Because of the reality of energy industry in China, nation owned companies and national institutes should still play important roles in research.

\section{Acknowledgment}

This research was sponsored by NSFC (No. 71125002)

\section{References}

[1] Lee, W. J., Sohn, S. Y., Lee, W. J., \& Sohn, S. Y, Patent analysis to identify shale gas development in china and the united states. Energy Policy, 74(74) (2014) 111-115.

[2] Energy Information Administration (EIA), World Shale Gas resources: An initial Assessment of 14 Regions Outside the United States. U.S. Department of Energy_EIA, Washington DC (2013).

[3] Sultan, N, The challenge of shale to the post-oil dreams of the arab gulf. Energy Policy, 60(6) (2013) 13-20.

[4] Jenner, S., \& Lamadrid, A. J, Shale gas vs. coal: policy implications from environmental impact comparisons of shale gas, conventional gas, and coal on air, water, and land in the united states. Energy Policy, 53(1) (2013) 442-453

[5] Sultan, N, The challenge of shale to the post-oil dreams of the arab gulf. Energy Policy, 60(6) (2013) 13-20.

[6] Nyman, Jonna, The quest: energy, security and the remaking of the modern world - by daniel yergin. Political Studies Review, 10(3) (2012) 428-429.

[7] Tian, L., Wang, Z. M., Krupnick, A., and Liu, X. L, Stimulating shale gas development in China: A comparison with the US experience, Energy Policy, 75(2014) 109-116 